\section{Sweat chloride is not a useful marker of clinical response to Ivacaftor}

Clinical trials have revealed that Ivacaftor significantly reduces sweat chloride in patients with cystic fibrosis who carry the G551D mutation. This finding has been incorporated into the commissioning guidelines in the UK with a sweat chloride reduction of $30 \%$ or below $60 \mathrm{mmol} / \mathrm{L}$, specified as the main criteria for continued funding of Ivacaftor for individual patients. In a cohort of 24 adults who were prescribed Ivacaftor, there was no correlation between absolute or relative reductions in sweat chloride and improvements in lung function. This questions the validity of sweat chloride as a surrogate marker of clinical efficacy.

\section{INTRODUCTION}

The development of the targeted cystic fibrosis transmembrane regulator (CFTR) potentiator Ivacaftor has significantly altered the landscape for cystic fibrosis therapeutics. In large phase III clinical trials, Ivacaftor has normalised sweat chloride and resulted in significant increases in pulmonary function and weight in suitable patients. The UK commissioning requirements for Ivacaftor require a reduction in sweat chloride of $30 \%$ from baseline, or below $60 \mathrm{mmol} / \mathrm{L}^{1}$ We prospectively assessed the relationship of sweat chloride with clinical outcomes in patients receiving Ivacaftor treatment.

\section{METHODS}

Ivacaftor naïve patients attending our centre carrying the G551D mutation who commenced therapy following national

Figure 1 Scatter plot revealing relative change in sweat chloride at 2 months following Ivacaftor to relative change in pulmonary function at 1 month following Ivacaftor. Each diamond represents a single subject. funding approval were included. Baseline sweat chloride were recorded, and repeated at 2 months. Baseline pulmonary function, height and weight were recorded and repeated at monthly visits for 3 months.

\section{RESULTS}

In 24 subjects, mean $\mathrm{FEV}_{1}$ per cent predicted increased from 64.3 to $73.4 \%$ at 1 month $(\mathrm{p}<0.001)$ and mean body mass index (BMI) improved from $22.1 \mathrm{~kg} / \mathrm{m}^{2}$ to $22.7 \mathrm{~kg} / \mathrm{m}^{2} \quad(\mathrm{p}=0.002)$. Sweat chloride decreased significantly at 2 months (median $114-51 \mathrm{mmol} / \mathrm{L}, \mathrm{p}<0.001)$. This improvement was not correlated in absolute or relative terms with improvements in spirometry (figure 1) or BMI. Initial sweat chloride responses did not meet the prespecified criteria at 2 months in four subjects, two of whom did meet criteria on repeat testing. In one subject the suboptimal response was attributed to a single missed dose. Two subjects $(8 \%)$ with absolute $\mathrm{FEV}_{1}$ improvements of $17 \%$ and $15 \%$, have to date failed to meet continuation criteria.

\section{DISCUSSION}

These data suggest that sweat chloride is not a good surrogate measure of clinical response to Ivacaftor, nor does it represent a valid criterion for drug discontinuation. This is important in the context of the requirements for Ivacaftor prescription in the UK. It raises the possibility that some 'responders' may have enforced drug discontinuation on the basis of a non-validated surrogate marker of efficacy.

It has already been reported that sweat chloride response did not correlate with $\mathrm{FEV}_{1}$ improvement in the phase III clinical trials. ${ }^{2}$ By reporting on relative changes, our data may better account for a potentially heterogeneous group at baseline and enhances the fact that no correlation exists. Additionally, although sweat chloride has been proposed as a sensitive and specific predictor of subsequent improvement in lung function for patients treated with Ivacaftor, the thresholds for response were lower than those required by UK commissioners and the poor negative predictive value of the sweat chloride response meant that it was unsuitable as a clinical test. ${ }^{3}$ Finally, as a marker of adherence, sweat chloride appears to be excessively sensitive to individual missed doses and gives no useful information about longer-term adherence.

The interaction between CFTR function and pulmonary status is complex, incorporating many possible explanations for the lack of correlation between sweat chloride and $\mathrm{FEV}_{1}$ responses. ${ }^{45}$ While it is important to ensure that resources are used appropriately, it is equally important to ensure that scientifically robust measures are used to assess therapeutic response to high-cost medications.

\section{Peter J Barry, ${ }^{1}$ Andrew M Jones, ${ }^{1,2}$ Anthony K Webb, ${ }^{1,2}$ Alexander R Horsley ${ }^{1,2}$}

${ }^{1}$ Manchester Adult Cystic Fibrosis Centre, University Hospital of South Manchester, Manchester, UK ; ${ }^{2}$ Institute of Inflammation and Repair, University of Manchester, Manchester, UK

Correspondence to Dr Peter Barry, Manchester Adult Cystic Fibrosis Centre, University Hospital of South Manchester, Southmoor Road, Wythenshawe, Manchester M23 9LT, UK; peter.barry@uhsm.nhs.uk

Contributors All authors were involved in the design of the study and collection of clinical data. PJB performed the data analysis. PJB drafted the final manuscript and all authors reviewed and made amendments.

Funding This study was funded by Manchester Adult Cystic Fibrosis Centre.

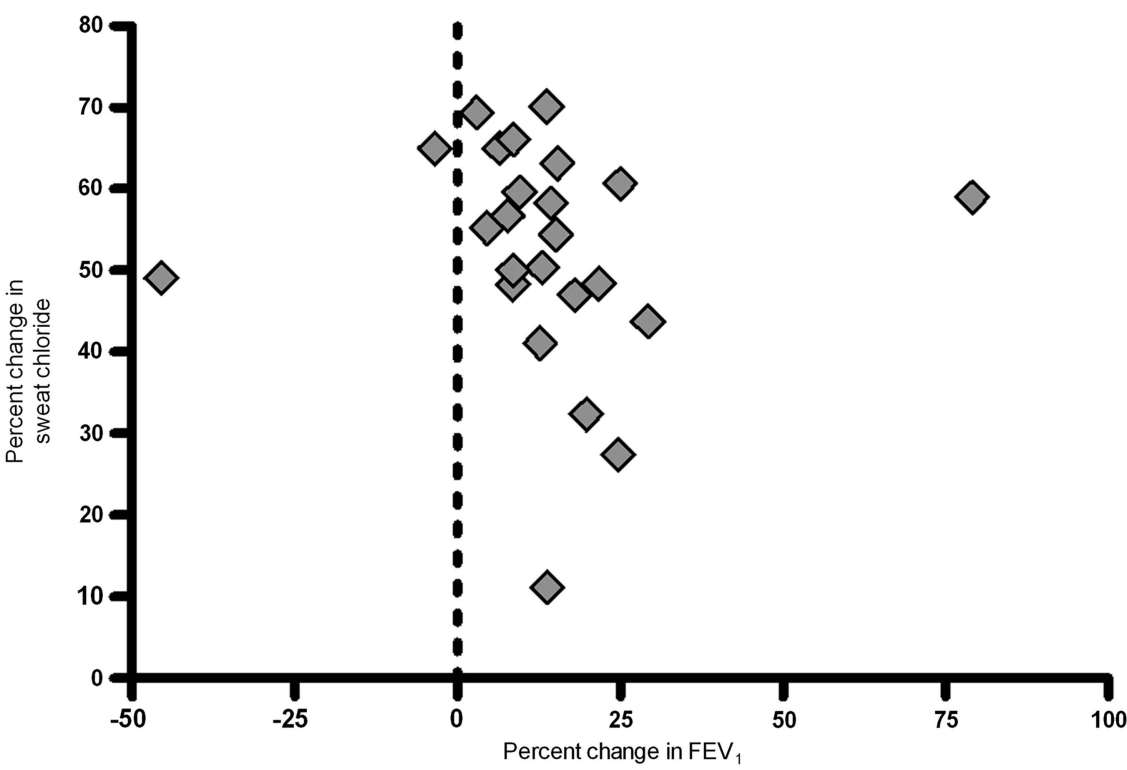


Competing interests None.

Provenance and peer review Not commissioned; externally peer reviewed.

To cite Barry PJ, Jones AM, Webb AK, et al. Thorax 2014;69:586-587.

Received 17 September 2013

Accepted 28 October 2013

Published Online First 20 November 2013

Thorax 2014;69:586-587.

doi:10.1136/thoraxjnl-2013-204532

\section{REFERENCES}

1 Clinical Commissioning Policy: Ivacaftor for Cystic Fibrosis. NHS Commissioning Board. http://www. england.nhs.uk/wp-content/uploads/2013/04/a01-p-b. pdf (accessed Aug 2013).

2 Center for Drug Evaluation and Research. Kalydeco (ivacaftor). Approval package. Silver Spring, MD: US Food and Drug Administration. http://www.accessdata.fda.gov/ drugsatfda_docs/nda/2012/2031880rig1s000Approv.pdf (accessed Aug 2013).

3 Seliger VI, Rodman D, Van Goor F, et al. The predictive potential of the sweat chloride test in cystic fibrosis patients with the G551D mutation. J Cyst
Fibros 26 Apr 2013. pii: S1569-1993(13)00040-4. doi: 10.1016/j.jcf.2013.03.004

4 Durmowicz AG, Witzmann KA, Rosebraugh CJ, et al. Change in sweat chloride as a clinical end point in cystic fibrosis clinical trials. The Ivacaftor exerpience. Chest 2013;143:14-18.

5 Dupuit F, Kälin N, Brézillon S, et al. CFTR and differentiation markers expression in non-CF and $\Delta$ F508 homozygous CF nasal epithelium. J Clin Invest 1995:96:1601-11. 